\title{
THE PROCESS OF WORD FORMATION TETUN LANGUAGE IN UMATOOS VILLAGE, KECAMATAN MALAKA BARAT, MALAKA DISTRICT, NUSA TENGGARA TIMUR
}

\author{
Ernesto Gustavo Tahu ${ }^{1}$, Bunali ${ }^{2}$ \\ ${ }^{1,2}$ Fakultas Keguruan dan Ilmu Pendidikan, Universitas Dr.Soetomo
}

Corresponding Author: egustavo.tahu@gmail.com

\begin{abstract}
Indonesia is an archipelago which consists of various ethnic groups. Each ethnic group has a regional language as its group identity. Regional languages have a very important role in social and cultural life. The people of Umato'os Village who generally use the local language of Tetun as a means of interaction, the formation process that occurs in Tetun in Umato'os Village is a change if the root word undergoes a process of forming a Tetun word. This type of research is descriptive qualitative. Data collection techniques were carried out by observation and interviews. Data analysis using the equivalent method. To test the validity of the data, researchers used source triangulation. The result of this research is that Tetum is one of the regional languages in the archipelago which is in the administrative area of Malacca district, East Nusa Tenggara province. Tetun language has its own uniqueness in the affixation process, the affixation process in Tetun not only undergoes a change but also the affixation process has shown a person's activity. Language can be used as a means of communication that is alive and fostered by the Tetum-speaking community as well as a means of developing regional culture. Tetun also serves as the Mother Language (first language) for the Tetun speaking community.
\end{abstract}

Keywords: word formation, language, tetun

\section{PROSES PEMBENTUKAN KATA BAHASA TETUN DI DESA UMATOOS KECAMATAN MALAKA BARAT, KABUPATEN MALAKA, NUSA TENGGARA TIMUR}

\begin{abstract}
Abstrak
Indonesia merupakan negara kepulauan yang terdiri atas berbagai etnik. Tiap-tiap etnik memilki bahasa daerah sebagai identitas kelompoknya. Bahasa daerah memilki peranan yang sangat penting dalam kehidupan bermasyarakat dan berbudaya. Masyarakat Desa Umato'os yang pada umumnya menggunakan bahasa daerah Tetun sebagai alat berinteraksi, proses pembentukan yang terjadi dalam Bahasa Tetun di Desa Umato'os merupakan suatu perubahan jika kata dasar tersebut mengalami suatu proses pembentukan kata bahasa Tetun. Jenis penelitian ini adalah deskritif kualitatif. Teknik pengumpulan data dilakukan dengan observasi dan wawancara. Analisis data menggunakan metode padan. Untuk menguji keabsahan data, peneliti menggunakan triangulasi sumber. Hasil penelitian ini adalah bahasa Tetun merupakan salah satu bahasa daerah yang ada di Nusantara yang berada di wilayah pemerintahan kabupaten Malaka propinsi Nusa Tenggara Timur. Bahasa Tetun memiliki suatu keunikan tersendiri dalam proses afiksasi, proses afiksasi dalam bahasa Tetun bukan saja mengalami suatu perubahan tetapi juga proses afikasasi tersebut sudah menunjukan aktifitas seseorang. Bahasa dapat dipakai sebagai alat komunikasi yang hidup dan dibina oleh masyarakat penutur bahasa Tetun juga berfungsi sebagai sarana pengembangan budaya daerah. Bahasa Tetun juga berkedudukan sebagai Bahasa Ibu (bahasa pertama) bagi masyarakat penutur Tetun.
\end{abstract}

Kata Kunci: pembentukan kata, bahasa, tetun

\section{Pendahuluan}

Bahasa merupakan sistem lambang bunyi yang arbiter yang digunakan oleh para anggota kelompok sosial untuk bekerjasama, berkomunikasi dan mengidentifikasikan diri, Kridalaksana (1983:40) danjuga Kentjono (1982:40) mengatakan bunyi bahasa itu diatur oleh tata bunyi bahasa itu diatur oleh tata bunyi, karena itulah bahasa merupakan sistem bunyi.

Kumpulan bunyi untuk menyebut sesuatu di luar biasanya tidak bisa diatur secara ketat, tetapi semua penutur berkomunikasi, sekaligus mengenal jati diribahwa diri manusia dapat diekspresikan oleh bahasa. Oleh karena itu, bahasa mempunyai sistem yang sifatnya mengatur. 
Jurnal DISASTRI (Pendidikan Bahasa dan Sastra Indonesia)

Volume 2, Nomor 3, Desember 2020| P-ISSN : 2716-4114 | E-ISSN: 2722-3329

Bahasa merupakan suatu lembaga yang memiliki pola-pola atau aturanaturan yang dipatuhi dan digunakan (kadang-kadang tanpa sadar) oleh pembicara dalam komunikasi untuk saling memahami.

Indonesia merupakan negara kepulauan yang terdiri atas berbagai etnik. Tiap-tiap etnik memiliki bahasa daerah sebagai identitas kelompoknya. Sebagai identitas kelompok, bahasa daerah memiliki peranan yang sangat penting dalam kehidupan bermasyarakat dan berbudaya. Bahasa daerah melekat erat dengan seluruh aspek kehidupan dan prilaku manusia sebagai bagian dari suatu masyarakat yang berbudaya. Dengan demikian dapat dikatakan bahwa bahasa merupakan media berkomunikasi yang berperan penting dalam kehidupan bermasyarakat baik secara eksternal maupun internal (Muhamad, 2011:184).

Secara umum, morfologi adalah sebagian dari ilmu bahasa yang membicarakan atau mempelajari seluk-seluk struktur kata serta pengaruh perubahan-perubahan struktur kata terhadap arti kata Ramlan (1978:2). Lebih lanjut menurut Nida (1974:1) mengatakan bahwa morfologi adalah suatu kejadian tentang morfem-morfem dan penyusunan morfem dalam rangka pembentukan kata. Morfologi adalah ilmu yang mempelajari tentang bentuk-bentuk dan pembentukan kata Chaer (2008:3).

Morfologi dapat dipandang sebagai subsistem yang berupa proses yang mengolah leksem menjadi kata. Dengan perkataan lain, yang berperan sebagai masukan (input) dalam proses itu ialah leksem sebagai satuan leksikal, sedangkan kata sebagai satuan gramatikal berperan sebagai keluaran (output). Dalam proses ini, kecuali dalam proses derivasi zero (leksem menjadi kata tunggal tanpa perubahan apaapa), leksem bukan hanya beruba bentuknya melainkan juga memperoleh makna baru, yang disebut sebagai makna gramatikal, sedangkan makna semula, yakni leksikal, sedikit banyak tidak berubah. Jadi output proses ini yaitu kata merupakan suatu kesatuan yang dapat dianalisis atas komponenkomponen yang disebut morfem Kridalaksana (2007:10).

Proses pembentukan kata yang terjadi dalam Bahasa Tetun di Desa Umato'os, Kecamatan Malaka Barat Kabupaten Malaka merupakansuatu perubahan jika kata dasar tersebut mengalami suatu proses afiksasi atau proses pembentukan kata. Proses afiksasi kata dalam bahasa Tetun memiliki tujuan untuk menyampaikan suatu maksud tertentu kepada masyarakat pengguna bahasa atau dialeg tersebut, sehingga orang tersebut bisa mengetahui atau memahami betul-betul dari maksud yang disampaikan.

Bahasa Tetun merupakan salah satu bahasa daerah yang ada di Nusantara yang berada di wilayah pemerintahan kabupaten Malaka propinsi Nusa Tenggara Timur. Bahasa Tetun memiliki suatu keunikan tersendiri dalam proses afiksasi, proses afiksasi dalam bahasa Tetun bukan saja mengalami suatu perubahan tetapi juga proses afiksasi tersebut sudah menunjukan aktifitas seseorang. Bahasa dapat dipakai sebagai alat komunikasi yang hidup dan dibina oleh masyarakat penutur bahasa Tetun juga berfungsi sebagai sarana pengembangan budaya daerah. Bahasa Tetun juga berkedudukan sebagai Bahasa Ibu (bahasa pertama) bagi masyarakat penutur Tetun. Dalam proses morfologi bahasa Tetun yang terjadi apabilakata dasar mengalami proses afiksasi mak- (menyatakan kata kerja) contohnya: pada kata dasar fa'en jika tambahkan afiks mak- maka akan muncul makna gramatikal mak-fa'en yaitu orang yang pekerjaannya menjual atau disebut penjual. Pada kata dasar lirin(dingin)jika tambahkan afiks ha-maka akan muncul makna gramatikal ha-lirin mendinginkan yaitu melakukan pekerjaan mendinginkan. Pada kata dasar sukat (ukur) jika ditambahkan afiks samaka akan muncul makna gramatikal sa-sukat (pengukur) yaitu alat untuk mengukur. Pada kata dasar loke (buka) jika ditambahkan afiks nak- maka akan muncul makna gramatikal nakloke (terbuka). Pada kata dasar rai (simpan) jika tambahkan afiks hak-maka akan muncul makna gramatikal hak-rai (menyimpan). Pada kata 
Jurnal DISASTRI (Pendidikan Bahasa dan Sastra Indonesia)

Volume 2, Nomor 3, Desember 2020| P-ISSN : 2716-4114 | E-ISSN: 2722-3329

dasar fihir (pilih) jika ditambahkan afiks fa- maka akan muncul makna gramatikal fa-fihir (memilih). Pada kata dasar korus (parut) jika ditambahkan afiks $k a$ - maka akan muncul makna gramatikal ka-korus (memarut). Pada kata dasar mos (bersih) jika ditambahkan afiks na- maka akan muncul makna gramatikal na-mos (membersih)Bahasa Tetun digunakan oleh sub etnik Tetun dalam berkomunikasi sehari-hari oleh masyarakat tuturnya. Oleh karena itu, dalam penelitian ini penulis menganggap bahasa Tetun merupakan bahasa daerah yang harus dijaga oleh masyarakat Desa Umato'os yang harus tetap dilestarikan dan dijaga dengan adanya persaingan antar bahasa asing yang semakin ketat agar bahasa Tetun tidaklah hilang atau punah dan agar tetap digunakan pada generasi yang akan datang.

\section{Metodologi Penelitian}

Jenis penelitian ini adalah deskritif kualitatif karena tujuan yang hendak dicapai sehubungan dengan topik peneliti ini adalah berusaha menggambarkan atau memaparkan mengenai data yang diperoleh mengenai suatu peristiwa kemudian membuat simpilan berdasarkan masalah-masalah yag telah ditetapkan dan bertujuan membuat deskripsi terhadap situasi, kejadian atau peristiwa, menginterpretasikanya dan berusaha menangkap (memahami) makna yang terkandung dibalik situasi atau peristiwa yang dimaksud. Data dalam penelitian ini adalah bahasa yang dituturkan oleh penutur asli bahasa Tetun. Teknik pengumpulan data dilakukan dengan observasi dan wawancara. Analisis data menggunakan metode padan. Metode padan dibedakan menjadi dua, yaitu teknik dasar dan teknik lanjutan. Teknik dasar yang digunakan pada penelitian ini adalah teknik pilah unsur penentu (PUP) yang alatnya berupa daya pilah yang bersifat mental yang dimiliki oleh penelitinya. Sedangkan teknik lanjutan yang digunakan adalah teknik hubung banding membedakan (HBB). Teknik ini digunakan untuk menemukan fonem vocal dan fonem konsonan bahasa Tetun dalam kata yang sudah dicarikan. Untuk menguji keabsahan data, peneliti menggunakan triangulasi sumber.

\section{Pembahasan}

Berdasarkan hasil analisis data diperoleh pembentukan kata dalam bahasa Tetun yaitu:

1. Prefiks.

Dalam bahasa Tetun mengenal 10 buah afiks yang terdiri dari 8 buah afiks yaitu, mak-, sa-, nak-, hak-, fa-, na- dan ka-yang berkedudukan sebagai prefiks dan 1 buah afiks $h a$ - yang berkedudukan sebagai konfiks serta 2 buah afiks $-k$,dan -ten yang berkedudukan sebagai sufiks.

Lihat contoh di bawah ini merupakan prefix $m a k$ -

a) Mate 'mati' menjadi

Mak-mate artinya 'yang meninggal'

b) Fa'en 'jual' menjadi

Mak-fa'en artinya 'yang meningal'

c) Sosa 'beli' menjadi

Mak-sosa artinya 'membeli'

d) Kaer 'pegang' menjadi

Mak-kaer artinya 'yang memegang'

e) Hemu 'minum' menjadi

Mak-hemu artinya 'yang minum'

f) Huit 'cubit' menjadi

Mak-huit artinya 'yang mencuit'

g) Toba 'tidur' menjadi

Mak-toba artinya 'yang tertidur'

h) Ki'ik 'kecil' menjadi Mak-ki'ik artinya 'yang terkecil'

i) Kiak 'yatim' menjadi Makiak artinya 'yang mengasuh'

j) Sar 'sapu' menjadi Mak-sar artinya 'yang menyapu'

k) De'an 'memarahi menjadi 
Jurnal DISASTRI (Pendidikan Bahasa dan Sastra Indonesia)

Volume 2, Nomor 3, Desember 2020| P-ISSN : 2716-4114 | E-ISSN: 2722-3329

Mak-de'an artinya ' yang
memarahi'

l) $H e^{\prime} u k$ 'tari' menjadi

Mak-he'uk artinya 'yang menari'

m) Hakat 'hasta' menjadi

Mak-hakat artinya ' yang
menghasta'

Prefiksa mak- menunjukan kepada subjek yang membentuk kata kerja.Dari contoh di atas dua perbedaan antara mak- dan maditentukan dari aspek fonologi atau bunyi.Mak- digunakan apabila mengikuti kata dasar yang berkonsonan, dan ma- ditentukan oleh /h/ dari dasar /ha/. Perbedaan kedua imbuhan mak- diakhiri dengan -n dan ma- diakhiri fonem -k dan lain sebagainya seperti:

Contoh kalimat:

1. Ema mak-fa'en na'ak

Orang yang menjual mengatakan "penjual mengatakan"

2. Ema mak-sosan na'ak

Orang yang membeli mengatakan "pembeli mengatakan"

3. Bele maki'ak oa nia to'o bot

"bias kamu mengasuh anak itu sampai dewasa"

4. Keta mak-te'ur mo nia "jangan kamu berkelahi dengan dia"

5. O mak-hakat modi liman du'uk Kamu hasta bawa tangan sendiri "kamulah yang menghasta dengan tangan kamu sendiri"

Prefiks sa- yang berfungsi membentuk kata kerja Contoh:

1. Sobak 'terkam' mejadi Sa-sobak artinya 'menerkam'

2. Sukat 'ukur' menjadi Sa-sukat artinya 'pengukur'

3. Solok 'kirim' menjadi Sa-solok artinya 'mengirim/kiriman'

4. Suku 'tancap' menjadi Sa-suku artinya 'mempengaruhi'
Sedangkan untuk contoh kalimat di bawah ini yaitu:

1. Asu ne'e ba sa-sobak nola oa ne'e. Anjing ini pergi menerkam anak ini

2. Hau ba sosa sa-sukat Saya pergi beli pengukur "saya pergi membeli pengukur"

3. Nia nodi sa-solok ba ha'u Dia bawa kiriman pergi saya "Dia membawa kiriman kepada saya"

4. Nia ne'e ba sasuku ema sia Dia ini pergi mempengaruhi orang mereka "dia yang mempengaruhi mereka"

Selanjtutnya, prefiks nak- membentuk kata kerja. Contoh:

1. Loke 'buka' menjadi Nak-loke artinya 'terbuka'

2. Lulun 'gulung' menjadi Nak-lulun artinya 'tergulung'

3. Feur 'putar' menjadi Nak-feur artinya 'terputar' Contoh kalimat:

1. Odamatan ne'e na'in nak-loke Pintu ini permilik terbuka "pintuini terbuka sendiri"

2. Rai klaran ne'e nakfeur Tanah tengah ini terputar 'bumi ini terputar'

Prefiks hak- yang berasal dari kata benda yang berfungsi membentuk kata kerja.

Contoh:

a. Masin 'garam' menjadi

Hak-masin artinya 'memohon'

b. Rai 'simpan' menjadi Hak-rai artinya 'menyimpan'

Berikut ini contoh kalimat dengan prefiks hak- yaitu.

a. Hak-masin ba ema bot sia Memohon pergi orang mereka "pergi memohon kepada pemimpin"

b. Ha'u mak hak-rai taha ne'e. Saya yang menyimpan parang ini "saya yang menyimpan parang ini"

Prefiks hak- yang berasal dari kata kerja intransitive yang berfungsi membentuk kata kerja transitif. Contoh:

a. Te'ur 'kejar' menjadi Hak-te'ur artinya 'bertarung' 
Jurnal DISASTRI (Pendidikan Bahasa dan Sastra Indonesia)

Volume 2, Nomor 3, Desember 2020| P-ISSN : 2716-4114 | E-ISSN: 2722-3329

b. Fera 'bela' menjadi

Hak-fera artinya membelah

c. Tuku 'pukul' menjadi

Hak-tuku artinya "memukul"

Contoh kalimat yang mengandung prefiks hak- yaitu:

1. Hobun ema hak-teur

Nonton orang bertarung

2. Ha'u hakfera ai

Saya membela kayu

3. Ha'u hak-tuku nia

Saya memukul dia

Dalam bahasa Tetun ada katakata tertetu yang bermakna ganda misalnya kata tuku bias berarti ganda dalam penggunaan bahasa setiap harinya, yang artinya menunjuka pada jam dinding, menempa, dan tinju atau pukul tergantung pada pengunaan kalimat atau sesuai dengan situasi yang ada. Contoh kalimatnya di bawah ini.

a. Tuku hira ti'an?

Jam berapa telah?

"sudah jam berapa?"

b. Sei hobun ema tuku malu

Masih kami nonton orang pukul saling

"kami masih nonton orang saling tinju"

Selanjutnya Prefiks $f a-$ dapat berupa:

1. Prefik $f a-$ yang berasal dari kata kerja intransitif yang membentuk kata kerja transitif. Contoh:

a. Fihir 'pilih' menjadi

Fafihir artinya 'suka memilih'

b. Fiar 'percaya' menjadi

Fafiar artinya 'kepercayaan'

Contoh kalimat:

a. Feto ne'e fafihir mane to'o

Wanita ini suka memilih laki-laki sampai

"wanita ini suka memilih pasangan"

b. Amikan fafiar ne,e bama na'i maromak

Kami kepercayaan ini kepada anak Tuhan 'kepercayaan kami kepada Tuhan'

2. Prefiks $f a$ - yang berasal dari kata kerja berfungsi membentuk kata benda.

Contoh:

a. Futu 'ikat' menjadi Fa-futun artinya 'ikatan'

b. Furin 'busa' menjadi Fa-furin artinya 'berbusa'

c. Fo'at 'jerat' menjadi Fa-fo'at artinya 'menjerat'

d. Fota 'pukul' menjadi Fa-fota artinya 'alat memukul' Contoh kalimat:

a. Dos nia fa-futun kbit ka lale Dos itu ikatan kuat atau tidak "ikatan dos itu kuat atau tidak"

3. Prefiks fa- yang berasal dari kata sifat berfungsi membentuk kata sifat.

Contoh:

a. Matak 'mentah' menjadi

Fa-matak artinya 'amis'

Contoh kalimaat:

a. Na'an ne'e famatak liu

Ikan ini amis lewat

"ikan ini terlalu amis"

Selanjutnya Prefiks $k a-$ yang berasal dari kata kerja yang berfungsi membentuk kata benda.

Contoh:

a. Fe'ur 'memutar' menjadi Ka-feur artinya 'gasing'

b. Korus 'parut' menjadi Ka-korus artinya 'memarut'

c. Teri 'pangkas' menjadi Ka-teri artinya 'gunting' Contoh kalimat:

a. Kafe'ur halo hosi ai "gasing terbuat dari kayu" Prefiks na-dapat berupa:

1. Prefiks na-yang berasal dari kata sifat yang berfungsi membentuk kata kerja.

Contoh:

a. Maus 'jinak' menjadi 
Jurnal DISASTRI (Pendidikan Bahasa dan Sastra Indonesia)

Volume 2, Nomor 3, Desember 2020| P-ISSN : 2716-4114 | E-ISSN: 2722-3329

Na-mau's

'menjinak/membujuk'

b. Mos 'bersih' menjadi

Na-mos artinya 'membersih'

c. Manas 'panas' menjadi

Na-manas artinya 'memanasi'

d. Mon 'jernih' menjadi

Na-mon artinya 'menjernihkan'

e. Moe 'malu' menjadi

Na-moe artinya 'mempermalukan'

Contoh kalimat:

a. Namos krehut iha uma laran

Membersihkan kotoran ada rumah dalam

"membersihkan kotoran di dalam rumah"

Dalam bahasa Tetun prefiks nadapat ditujukan pada diri orang ketiga tunggal yang menyatakan seseorang dalam melakukan sesuatu.

Contoh kalimat yang membentuk pertanyaan:

a. Sei nalo sa?

Masih buat apa?

"dia masih berbuat apa?

b. Sei namos krehut

Masih bersihkan kotoran

"masih bersihkan kotoran"

Dari contoh diatas tidak terjadi pemborosan kata na- seperti pada contoh yang membentuk kalimat sebelumnya diatas. Hal ini terjadi karena dalam bahasa tetun apabila digunakan pada kalimat Tanya maka nasendiri sudah menunjukan pada diri orang ketiga tunggal tetapi bila digunakan dalam kalimat biasa yang menjelaskan tentang seseorang dalam melakukan sesuatu aktifitas, maka akan terjadi pemborosan kata pada prefiks na- yang tertuju pada orang ketiga tunggal tersebut.

2. Prefiks $n a$ - yang digabungkan dengan kata dasar berfungsi membentuk kata kerja.

Contoh:

a. Toba 'tidur' menjadi Na-toba artinya 'meniduri'

b. Tun 'turun' menjadi Na-tun artinya 'menurunkan'

c. Sa'e 'naik' menjadi Na-sa'e artinya 'menaikan' Contoh kalimat:

a. Nia sei ba natoba oa Dia masih pergi meniduri anak "dia masih meniduri anak"

2. Konfiks Prefiks ha- terdiri atas dua yaitu:

1. Prefiks ha-yang berasal dari kata sifat berfungsi membentuk kata kerja. Contoh:

a. Manas 'panas' menjadi Ha-manas artinya 'memanasi'

b. Lirin 'dingin' menjadi Ha-lirin artinya 'mendinginkan'

c. Mos 'bersih' menjadi Ha-mos artinya 'membersihkan'

d. Ma'ar 'tebal' menjadi Ha-ma'ar artinya 'mempertebal'

e. Mamar 'kenur' menjadi Ha-mamar artinya ' mengendurkan'

f. Morin 'harum' menjadi Ha-morin artinya 'mengharumkan'

g. Lakon 'hilang' menjadi Ha-lakon artinya 'menghilangkan'

h. Moe 'malu' menjadi Ha-moe artinya 'mempermalukan' Contoh kalimat:

1. Itamosti ha-manasbesi ne'e. Kita harus memanasi besi ini "kitaharus memanasi besi ini"

2. Ita mosti ha-lirin we ne'e. Kita harus mendinginkan air ini. "kita harus memdinginkan air ini"

3. Mai ita ha-mos ke'an ne'e. Mari kita membersihkan kamar ini. "mari kita membersikan kamar ini"

4. Mai ita ha-ma'ar ai ne'e 
Jurnal DISASTRI (Pendidikan Bahasa dan Sastra Indonesia)

Volume 2, Nomor 3, Desember 2020| P-ISSN : 2716-4114 | E-ISSN: 2722-3329

Mari kita mempertebalkan kayu ini "mari kita mempertebalkan kayu ini"

5. Ita keta hamamar itakan hakara Kita jangan mengendurkan kembali kita niat

"kita jangan mengendurkan kembali niat kita"

6. Mai ita ha-morin itakan leo ne'e.

Mari kita mengharumkan kita punya kampung ini.

"mari kita mengharumkan nama baik kampung kita"

7. Mai ita ha-lakon brain knuhar ne'e.

Mari kita menghilangkan barang bau ini

"mari kita menghilangkan bauh busuk ini"

8. Ita keta hamoe malu

Kita jangan mempernalukan saling "kita jangan saling mempermalukan"

Dari contoh di atas dapat diketahui bahwa kata yang sudah diimbuhkan dengan dasar dan dibentuk dalam kalimat seperti 'haluli' akan secara otomatis ditujukan pada diri orang pertama jamak. Dan apabila ditujukan kepada kata ganti orang lain maka akan berubah, bukan bunyi /h/ tetapi akan muncul fonem lain. Hal ini terjadi karena adanya pengaruh lingkungan dimasukinya atau sesuai dengan pengunaan kalimat dalam mengungkapkan masyarakat dalam berkomunikasi.Seperti kata ha- sendiri 'makan' secara otomatis ditunjukan pada orang pertama jamak karena bahasa Tetun berubah sesuai subjek kalimat.

Bila ditunjukan pada kata ganti orang pertama tunggal:

Contoh kalimat :

1. Kaluli ka na'an bibi
Saya berpantang makan danging kambing "saya berpantang makan daging kambing"

2. Kamos uma laran

Saya membersikan rumah dalam

"saya membersikan dalam rumah"

3. Ha'u ka'ak sa ba emi

Saya katakana apa pergi kalian

"saya mengatakan apa kepada kalian"?

4. Kalakon loit wain iha basar

Saya menghilangkan uang banyak ada pasar

"saya menghilangkan banyak uang di pasar"

5. Kamos fos iha uma laran

Saya membersikan beras ada di dalam rumah "saya membersikan beras di dalam rumah"

Pada contoh di atas munculnya fonem /k/ pada predikat kalimat karena ditujukan pada kata ganti orang pertama tunggal.

2. Prefiks ha- yang berasal dari kata kerja intransitif yang berfungsi membentuk kata kerja transitif.

Contoh:

a. Toba 'tidur' menjadi Ha-toba artinya 'menidurkan'

b. Tama 'masuk' menjadi Ha-tama artinya 'menjebloskan'

c. $B e^{\prime} o$ 'pecah menjadi Ha-be'o artinya 'memecahkan'

d. Lakon 'hilang' menjadi Ha-lakon artinya menghilangkan'

e. Kluan 'luas' menjadi Ha-kluan artinya 'memperluas'

3. Sufiks

Dalam bahasa Tetun, sufiks $-k$ sebagai kata ganti orang ketiga tunggal, baik dalam fungsinya sebagai pelaku atau pemilik.

1. Nia 'dia' menjadi

Niak artinya 'kepunyaannya/kepunyaan dia'

2. Ha'u 'saya' menjadi

$H a$ 'uk artinya 'kepunyaanku'

Contoh kalimat:

1. Buku ne'e niak

Buku ini kepunyaannya

'buku ini kepunyaannya' 
Jurnal DISASTRI (Pendidikan Bahasa dan Sastra Indonesia)

Volume 2, Nomor 3, Desember 2020| P-ISSN : 2716-4114 | E-ISSN: 2722-3329

2. Buku ne'e ha'uk

Buku ini kepunyaanku

mengasuh anak itu sampai dewasa "kamu bias mengasuh anak itu sampai dewasa"

'buku ini kepunyaanku'

Dalam bahasa Tetun, sufiks ten berperan sebagai kata ganti sifat

1. Beik 'rakus' menjadi

Beik-ten artinya 'perakus'

2. At 'rusak' menjadi

At-ten artinya 'perusak'

3. Kmakur 'malas' menjadi

Kmakur-ten artinya 'pemalas'

Contoh kalimat:

1. O ne'e beikten tebes

Kamu ini perakus betul

'kamu ini betul-betul perakus'

2. Oa ne'e atten tebes

Anak ini perusak betul

'anak ini betul-betul perusak'

3. Oa ne'e kmakurten tebes

Anak ini pemalas betul

'anak ini betul-betul pemalas

\section{Simpulan}

Berdasarkan hasil penelitian analisis

1. Proses Pembentukan kata yang terjadi dalam Bahasa Tetun di Desa Umato'os, Kecamatan Malaka Barat Kabupaten Malaka merupakan suatu perubahan jika kata dasar tersebut mengalami suatu proses afiksasi atau proses pembentukan kata. Proses afiksasi kata dalam bahasa Tetun memiliki tujuan untuk menyampaikan suatu maksud tertentu kepada masyarakat pengguna bahasa atau dialeg tersebut, sehingga orang tersebut bisa mengetahui atau memahami betul-betul dari maksud yang disampaikan.

2. Makna yang timbul saat terjadi proses afiksasi Bahasa Tetun, maka terjadi pula perubahan makna dari bentuk asal menjadi bentuk turunan Makna akan diberikan contoh kalimat sebagai berikut ini. Makfa'en na'ak Penjual mengatakan "penjual mengatakan" Maksosan na'ak Yang menjual mengatakan "penjual mengatakan" Bele mak-kiak oa nia to'o bot Bias kamu 